\title{
The Impact of Artificial Intelligence in Accounting Work: Expert Systems Use in Auditing and Tax
}

\author{
Daniel E. O'Leary ${ }^{1}$ and Robert M. O'Keefe ${ }^{2}$ \\ 'School of Business, University of Southern California, Los Angeles, USA \\ ${ }^{2}$ Department of Information Systems \& Computing, Brunel University, Uxbridge, UK
}

\begin{abstract}
This paper uses Perrow's sociological framework as a basis for a comparative organisation analysis of the impact of expert systems on organisational issues. The study analyses the relative impact of expert systems on two different types of accounting work: auditing and tax. The results indicate an impact on factors that ultimately improve productivity. The aggregate results indicate that expert systems are found to allow the user substantial control of search for solutions and discretion on whether to follow system recommendations, increased access to top management, and a decrease in the need for supervision. The systems allow the user the ability to solve a broader range of problems, while allowing the user the ability to perform more work. The comparison of auditing and tax expert systems indicates that audit systems seem to allow for greater control over search. Tax systems seem to allow more work to be done without supervision, make more decisions immediately, and allow the user to make a wider range of decisions.
\end{abstract}

Keywords: Knowledge-based systems; Accounting; Taxation; Organisation; Work

\section{Introduction}

A number of researchers have investigated the use of expert systems (ES) in accounting, auditing and tax (Michaelsen and Messier, 1987; Messier and Hansen, 1987). Other have considered the impact of differing development methodologies or organisational settings (Duchessi and O'Keefe, 1995). However, research has not systematically examined issues that lead to improvement in problem solving or the impact of ES on supervision. In addition, previous research primarily has focused on expected benefits derived from the technology and "conventional wisdom", rather than the impact on organisational roles.

The purpose of this paper is to discuss empirical evidence about the impact of ES on issues that influence organisations. In particular, the concern of this paper is the 
influence on supervision, access to top management, the range of decisions made, decision making discretion, and a number of similar organisational issues. A single domain, accounting, is chosen in order to normalise the influence of the domain. However, even in the context of that domain, it is acknowledged that there may be a differential impact on different kinds of accounting work, particularly auditing and tax. As a result, a comparative analysis of those different types of accounting activity is also made. Throughout, the empirical work is based on the theoretical constructs of Perrow $(1967,1970,1986)$.

\subsection{Basis of Analysis}

The analysis of ES is treated as the analysis of a general technology, i.e., a tool for performing work. The raw material for the ES technology becomes the knowledge and the information that is processed by the organisation to perform accounting work. Since those raw materials differ based on the type of work, there could be different effects of ES for different kinds of work.

This treatment of ES as a general technology is consistent with the research of Perrow $(1967,1970,1986)$ who argued that for the study of organisational work, technology is an important independent variable. Organisations' work is influenced by technologies resulting in different organisational and task structures. Thus, different types of work are influenced differently by ES.

Perrow's (1967) framework is based, in part, on the work of March and Simon (1958), with particular emphasis on "programmed tasks". Perrow's (1967) framework has been used as the basis for analysis in Information Systems (IS). For example, Daft and Macintosh (1978) provided a summary of some of Perrow's framework that resulted in categorising different types of IS. However, they did not use much of the Perrow framework and they did not do empirical analysis. (The portion of Perrow's framework that was not used is particularly relevant to the notions of productivity, as will be seen later.)

Perrow's framework has been the basis of substantial research on the impact of IT in general. Lynch (1974) and Withey et al. (1983) provided empirical assessments of the Perrow construct. In addition, in the analysis of the impact of technology on organisations, Perrow's work still receives substantial attention (e.g., Dean et al., 1992 and Orlikowski, 1992).

\subsection{Previous Research on Impact of ES}

Baldwin-Morgan (1995) presents a recent survey of some previous research on organisational impact in accounting. Her paper examines many of the key studies and the methodologies used to analyse organisational impact. She finds that only a few papers employ organisation theory as a basis of analysis. Similarly, much of the previous research on the impact of ES has focused on specific cases. For example, Sviokla (1990) examined the impact of XCON on Digital; Trewin (1996) examined the effect of ExperTax on Coopers and Lybrand; Baldwin-Morgan (1994) studied an auditing expert system. Although those studies provide insights into the impact of specific ES, such work is difficult to generalise. 


\subsection{This Paper}

This paper extends the research in O'Keefe et al. (1993) by using Perrow's organisational theory research to analyse the difference between the organisational impact of audit and tax ES. Unlike previous research, this paper provides a broad base of analysis, comparing results from the investigation of twenty-seven systems.

This paper proceeds as follows. Section 2 reviews and summarises some of Perrow's framework for comparative analysis. Section 3 establishes hypotheses for the expected impact of ES on accounting work. Section 4 summarises the instrument development and implementation. Section 5 reviews the findings and relates the findings to the hypotheses and Perrow's theory. Section 6 provides a brief summary.

\section{On Perrow's Framework for Comparative Analysis}

Perrow $(1967,1970,1986)$ developed a theory of comparative analysis of organisational behavior, suggesting that organisations be viewed primarily as systems for doing work. Accordingly, Perrow regards technology as an independent variable that influences the organisation of work. Different forms of technology impact the manner in which work is done. For the purposes of this paper the particular technology of interest is ES in accounting.

Perrow discussed two primary characteristics of technology that would directly impact the work process of organisations. First is the number or extent to which exceptions are encountered, while the second is the nature of the search process used when faced with the exceptions. Exceptions refer to the number of exceptional cases encountered in the specific work. An exceptional case is something that requires specific processing that differs from the norm; for example, a piece of raw material whose quality makes it unacceptable for immediate processing, or an unrully or talented student that a teacher must deal with in a different or innovative way. Perrow measures exceptions on a scale of low to high.

Search refers to the mechanism whereby a worker searches for and finds a method of dealing with exceptions. Search is assumed to lie along a spectrum of choices. At one end of the spectrum, search is conducted on a "logical" basis (for example, that captured by a computer program) (Perrow 1967, p. 196). At the other end, search processes are "nonroutine," where "...one draws upon the residue of unanalysed experience or intuition ..." (Perrow 1967, p. 196). These two dimensions are illustrated in Fig. 1(a), using the descriptors for the quadrants in Daft and Macintosh (1978).

Perrow stressed the organisational transformation of raw materials as a conversion process, noting that processing raw materials generally is the work done by organisations. Development of ES requires a raw material of domain knowledge, e.g., tax. Functioning accounting ES process both knowledge and data.

From Perrow's perspective, there are two dimensions in the analysis of the raw materials: understandability and stability. In the case of ES, the concern is with the understandability of the knowledge on which the system is based (ranging from well-understood to not well-understood). In particular, the key question is whether the knowledge is understood by all in a given department or by just a few experts. In 


\begin{tabular}{|c|c|c|}
\hline \multicolumn{3}{|l|}{ Search } \\
\hline Intuition & Craft & Research \\
\hline \multirow{2}{*}{ Logical } & Programmable & $\begin{array}{l}\text { Technical/ } \\
\text { Professional }\end{array}$ \\
\hline & Low & High \\
\hline
\end{tabular}

Fig. 1(a). Perrow's classification of work units.

addition, the other concern is the stability of the knowledge (ranging from stable to nonstable). For example, in the case of tax knowledge, we might expect at least yearly changes in the knowledge. These dimensions are summarised in Fig.1(b).

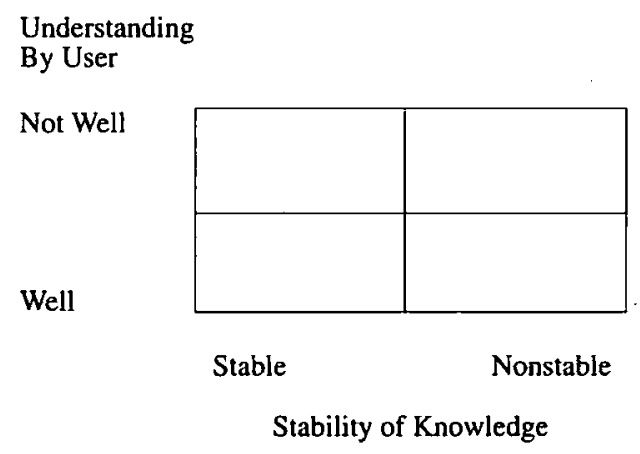

Fig. 1(b). Classification of knowledge processed.

According to Perrow, the task structure is influenced by two variables: control and coordination. Control has two components: degree of discretion possessed when carrying out a task; and power to generate resources and control various flow situations As noted by Perrow (1967: 198) discretion “... relates to choices among means anc judgments of the critical and interdependent nature of the tasks". Further, "powe affects outcomes directly because it involves the choices regarding basic goals an strategies". Perrow (1967) specified that coordination required analysis of th relationships within the specific group or department and with other groups involve in the processing of the raw material. The amount of coordination was delineated $b$ Perrow as, in part, a function of interdependence of groups. These three characteristic (discretion, power, and interdependence) were evaluated within the context of wheths they impact supervision or technological assistance with the technology. The mo: 
technologically complex problems would require technological assistance and business flow issues would require more general supervision. These variables are summarized in Fig. 1(c).

\begin{tabular}{|c|c|c|c|}
\hline & Discretion & Power & Group Interdependence \\
\hline \multicolumn{4}{|l|}{ Technical } \\
\hline Supervision & & & \\
\hline
\end{tabular}

Fig. 1(c). Task structure.

ES and other technologies place critical demands on organisations. Those technologies force changes in the transformation processes of organisations. Perrow $(1967,1970,1986)$ provides an organisational theoretic basis with which to investigate some of those demands, and in so doing, provides a basis with which to analyse the impact of ES. As a result, Perrow's work was used as the basis to generate a series of questions, summarized in the Appendix.

\section{Questions for Impact of ES on Work}

This section provides the theory for the questions that were used to test Perrow's (1967) framework. Each question (e.g., question 1 or "Q1") relating to the instrument is referenced here, and is used in the figures. In some cases, where there is expected to be a difference between the two types of accounting work studied here, there also is discussion relating to those issues. It is recognised that several of the questions are based upon attitudes or responses rather than simple data provision; we, therefore, do not present results as absolutes but only analyse differences between the two types of ES. This reduces the bias caused by requiring attitudinal responses.

\subsection{Search: Exceptions}

The first set of dimensions in the Perrow theory are the comparison of search and exceptions (Fig. 1(a)).

Search (Q1). As professionals, accountants are expected to control the general search for solutions. As a result, even if an ES is used, then control of search, should be left to the professionals, at least to a certain extent. However, there are likely to be differences between auditors and tax accountants in the control of the search, based on the nature of the work. As noted by Kelly et al. (1987: 167-168) “... auditors learn acceptance of processes that may diverge significantly from their own as long as they 'appear reasonable'." Thus, auditors would have substantial discretion of alternative processes. 
Much of the search in tax is driven by the goals and intent of the legal system and the taxpayer goals and constraints. For example, as noted by Michaelsen and Messier (1987, p. 13), " ... tax compliance consists of the preparation of a clients return". The nature of completing a return would limit the discretion of the tax accountant. The tax law and the return ultimately controls discretion and search. Similarly, in tax planning ES the concern is with (Michaelsen and Messier (1987: 13) "... ultimately maximizing taxpayer wealth, given the taxpayer's personal objectives and financial constraints". Thus, there exist specific goals and objectives, driving the search. As a result, auditors might be expected to have greater control of search than tax accountants.

Exceptions (Q2). Often ES are characterised as computer software that are designed to either capture expertise or act like an expert. Typically, that knowledge is "rule of thumb" or heuristics, aimed at diagnosing situations. Diagnostic systems of all kinds must elicit exceptions and then determine how to deal with those exceptions. As a result, ES are likely to capture a number of exceptions.

\subsection{Understandability: Stability}

Figure 1(b) summarises the factors of understandability and stability of the knowledge.

Understandability (Q3). Kelly et al. (1987: 168) note that auditors apparently “... do not have a set of clearly defined 'experts' whose technical skill find 'material' errors in an audit with significantly higher frequency than other auditors". Thus, we might expect expertise for the development of an ES to come from almost any part of the audit organisation. Similarly, a review of tax systems discussed in Michaelsen and Messier (1987) suggests that experts are likely to be different than the ultimate users of tax ES.

Amount and Stability (Q4). One way of measuring the amount of knowledge or other characteristics of the knowledge in an ES is the number of rules or frames. Dynamic environments require changes in the knowledge, and corresponding knowledge base. Thus, the stability of the knowledge in the particular domain can be measured using the frequency with which the rules are changed. Accounting knowledge, both auditing and tax, is subject to substantial change over time.

\subsection{Supervision/Technology: Interdependence}

Figure 1(c) summarises the interaction between supervision and the technology control of the ES.

Supervision: Interdependence (Q5). This is a function, at least in part, of the need to communicate with top management. The greater the interdependence, in that the worker must refer to or confer with a manager or supervisor, the greater the need for communication.

ES result in large quantities of knowledge being codified in computer programs. Coordination and control of that knowledge can require that top management become involved. In addition, Drucker (1988) suggests that with the introduction of computerbased systems there is a change in organisations, with greater use of "teams". This leads to a number of changes in supervisory relationships, resulting from the use of ES, including potentially greater communication with top management. 
As a result, greater access to top management, from ES implementation, is expected. There may be differences in that level of communication, depending on the type of accounting work. Typically, auditors are part of a team that solves a very large problem. Carmichael and Willingham (1989) characterise the "typical" audit engagement as having 11-13 people with a number of layers of personnel (5-6 staff, 3-4 seniors, 2 managers, and 1 partner). Individual auditors are allocated specific interacting activities, as part of the audit process. Unlike auditing, often tax problems are handled by individual tax accountants or at least smaller teams of accountants. The multiple layers and large numbers of personnel, inherent in audit engagement, could limit the access of lower level personnel to upper management. Thus, the use of ES in auditing and tax can result in different accessibility to top management.

Technology: Interdependence (Q6) is a function of the extent to which the user understands and can manipulate the technology, independent of the technician. Technicians of ES, typically referred to as knowledge engineers, are technical specialists, familiar with the process of acquiring knowledge for the system and representing that knowledge in specialized computer software. Consequently, there is substantial technical expertise associated with the process of building and maintaining an expert system. As a result, knowledge engineers may be located in a special department, separate from the users, typically an expert systems development department, an information systems department or a "technology department". As a result, this would suggest that users are not often developers of substantial ES.

\subsection{Supervision/Technology: Discretion}

As noted by Perrow (1967: 198), “...discretion involves judgments about whether close supervision is required on one task or another, about changing programs and about the interdependence of one's task with other tasks". Expertise embedded in ES can include supervisory activities or monitoring behavior so that supervisors need only intervene under certain circumstances. Thus, ES can reduce the need for supervision (Q7).

From a technology perspective the user's discretion is a function of their ability to ignore the assistance provided by the technology. In terms of the ES, this can mean the ability to disregard system recommendations. Since ES typically are developed to assist, users have discretion to ignore the recommendations made by the system (Q8).

\subsection{Supervision/Technology: Power}

Perrow (1967: 198) notes that "power affects outcomes directly, because it involves choices regarding basic goals and strategies". In the case of ES, such basic goals may include providing more rapid solutions or assisting the user to solve a wider range of problems or increasing the amount of work.

Since ES capture expertise, they can be used to delegate decision making downward. This would indicate that ES users could solve a broader range of problems than if they were not using the technology (Q9). 
In addition, since ES are computer-based technology, large quantities of data and knowledge can be sorted through very rapidly. Thus, it is likely that decisions can be made more rapidly than through other means (Q10). Supervisory power, with ES, would come from the ability to increase the amount of work that could be done, without supervision. Since the system would include much of the knowledge necessary to make decisions, it is likely that ES would allow for such an increase (Q11).

\section{Measurement Instrument and Use}

A test instrument was developed, and piloted on a developer of accounting ES and a faculty member. The instrument went through numerous revisions, for accuracy, length of time to complete and other aspects.

The instrument was distributed to 90 different developers of ES. All had been attendees at ES conferences or workshops on AI in Business, sponsored by the American Association for Artificial Intelligence. Fifty-nine returns were received, resulting in a $65 \%$ response rate. Analysis of the timing of the receipt of the responses did not result in evidence of a response bias. Of those 59 returns, we choose not to include the returns from some of the respondents since the systems were not operational (2), they were primarily research prototypes (8), or they were not accounting (auditing or tax) systems (5). A further 17 responses indicated that the respondents had not fully developed the system, the respondents were not able to divulge details of the development or implementation of the system, or the respondent was not developing any system. We were left with 27 usable responses providing information on 13 audit systems and 14 tax systems.

\section{Findings}

This section summarises the findings. First, overall results on the use of ES in accounting are reviewed. Second, the differences between tax and audit ES are analysed. Third, the data is summarised in the form of the models developed by Perrow (1967).

\subsection{Overall Results}

The overall mean results are summarised in Table 1 using the ordinal scales shown in the Appendix. We note the following:

- Question 1, the percentage of the time that the user controls the search, had a mean of between $26-50 \%$. Thus, rather than the system controlling search, the user appears to have substantial control.

- Question 2, the percentage of those rules relating to exceptions, had a mean of $26 \%$ to $50 \%$. Thus, ES appear designed to deal with exceptions.

- The result for questions 3 and 6 indicate that the average response is different from zero ("no"). As a result, in general it appears that the users are in different 
organisational groups from both the experts on which the system is based and the developers of the systems.

- Based on the frequency of system updating (question 4) accounting ES are relatively stable. Updates rarely occurred more often than yearly.

- The mean for question 5 is significantly different than zero. This indicates that there appears to be some increased access to top management resulting from the ES.

- The mean result from question 7 indicates that the ES provides "some reduction" in the need for supervision. Also, the result for question 8 indicates that the user has substantial discretion to disregard the system recommendations (51-75\%).

- The mean response for question 9 corresponds to at least "somewhat wider." Thus, the use of an ES results in the ability to address a wider range of problems than before the system was used.

- The results in question 10 indicate that more decisions can be made in a timely manner, when using the ES. Similarly, the findings for question 11 indicate that the use of an ES leads to the ability to do more work without the supervision that is required when an ES is not used.

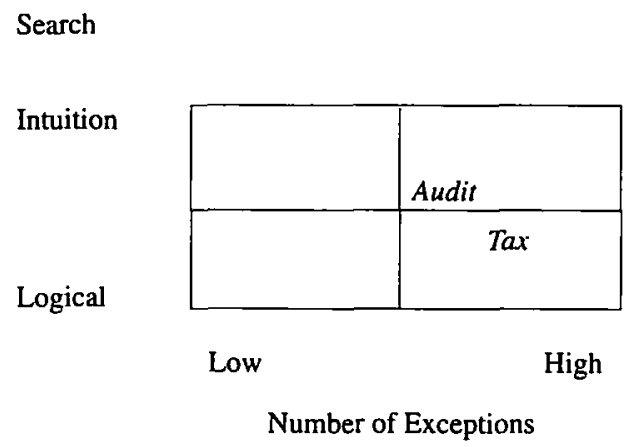

Fig. 2(a). Classification of work units for problems captured as ES audit and tax ES placed in the table. Placements are based on questions 1 (search) and 2 (exceptions).

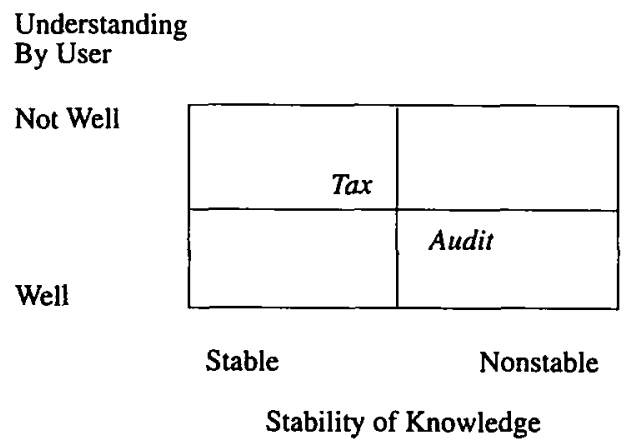

Fig. 2(b). Classification of knowledge processed by ES. Placements are based on questions 3 (understanding of knowledge by user) and 4 (stability). 


\subsection{Audit and Tax Systems: Differences}

Even though audit and tax are both types of "accounting" there were a number of noticeable and significant differences. Analysis of the means generates statistically significant results $(p<0.1)$ for five questions, indicating some important differences between audit and tax systems.

The control of the search, question 1, yielded substantially different results, with the difference significant at .04. Audit systems appear to allow the user greater control than do tax systems. Questions 6, 9,10 and 11 were all significant at the .1 level or better. In particular, more users seem to be developers in audit, and the user seems to be able to solve a greater increase in the number of problems in tax. Question 11, revealed that on average, tax ES seem to increase the ability to work without supervision more than audit ES.

The comparative (auditing and tax systems) results can be presented in the context of the tables summarising Perrow's framework. The average results were used to place audit and tax systems in the Perrow tables. The placement within the tables was based on rough interpolation within the range provided in the test instrument. These results are summarised in Fig. 2.

Interestingly, although tax ES are classifiable as technical/professional work activity, audit ES are classified as a research activity. Audit ES appear to be better understood but knowledge is unstable, whereas tax ES has more stable knowledge but are less well understood by user.

Table 1. Means and t-test of equal means

\begin{tabular}{lccc}
\hline Question/Explanation & Overall & Audit $(\mathrm{n}=13)$ & Tax $(\mathrm{n}=14)$ \\
\hline Proportion Late & .21 & .58 & .58 \\
0. No. of Rules (.91) & 3.27 & 3.25 & 3.29 \\
1. \% Time User Controls Search (.04) & 1.34 & 1.85 & 0.85 \\
2. No. for exceptions (.35) & 1.88 & 1.72 & 2.00 \\
$\begin{array}{l}\text { 3. Different Organisation Groups (.33) } \\
\text { Experts vs. Users }\end{array}$ & 0.41 & 0.31 & 0.50 \\
$\begin{array}{l}\text { 4. Frequency of updating (.17) } \\
\text { 5. Increased/Decreased Access to (.14) } \\
\text { Top Management }\end{array}$ & 1.30 & 1.54 & 1.07 \\
6. Different Organisation Groups (.08) & -0.22 & -0.09 & -0.37 \\
Developers vs. Users & & & 0.86 \\
7. Increase/Decrease Supervision(.12) & 0.70 & 0.54 & -1.35 \\
8. \% Time User has Discretion to (.10) & & & 2.42 \\
Disregard System & -1.11 & -0.83 & -1.50 \\
9. Wider/Narrower Range (.07) & 2.93 & 3.46 & -1.14 \\
$\begin{array}{l}\text { 10. More/Less Decisions Immediate(.09) } \\
\text { 11. More/Less Work w/o Supervision(.06) }\end{array}$ & -1.12 & -0.92 & -1.33 \\
\hline
\end{tabular}




\section{Conclusions}

This paper has focused on the impact of a technology (expert systems) on work processes (accounting), with particular emphasis on differences of effect on auditing and tax work.

Despite a small sample size, we have found some differences between auditing and tax ES. Perrow's theories of work and organisation allow us to understand these differences. What is perhaps most important is not the actual differences we found, but that differences exist. The impact of ES on work, and vice versa, means that impact of any ES implementation can not be predicted without understanding of the nature of the underlying work and knowledge.

See Appendix for corresponding questions. Results in ( ) after description are the individual levels of significance associated with the hypothesis that the means of the two groups are equal. Questions 1,6, 9, 10 and 11 show significant difference at $p<0.10$.

\section{Appendix: Questions on Instrument}

0 . Approximately how many rules and frames are there in the system?

$\begin{array}{lllll}0.0-20 & 1.21-50 & 2.51-100 & 3.100-500 & 4 .>500\end{array}$

1. To what extent does the user control alternative search strategies used by the system?

$\begin{array}{lllll}0.0 & 1.1-25 \% & 2.26-50 \% & 3.51-75 \% & 4.76-100 \%\end{array}$

2. How many of these are designed to deal with exceptions, i.e., non standard situation encountered by the user in the course of his or her job?
0.0 1. $1-25 \%$
2. $26-50 \% \quad 3.51-75 \%$
4. $76-100 \%$

3. Are the users of the system from a different organisational group or department than the experts?

1. Yes 0 . No

4. Approximately how often are new rules added or old rules deleted?
43
2
1
0
Daily Every Week Every Month Every Year Never

5. Has the system increased or decreased access to top management?
$\begin{array}{lllll}-2 & -1 & 0 & +1 & +2 \\ \text { Very much } & \text { Somewhat } & \text { No } & \text { Somewhat } & \text { Very Much }\end{array}$
Increased Increased Decreased Decreased

6. Are the users of the system from a different organisational group or department than the developing group? 1. Yes 0 . No

7. Does the use of the system reduce or increase the need for technical or managerial supervision when dealing with these exceptional occurrences?
$-2$
$-1$
$0+1$
Considerable Some No Some
$+2$
Increase
Increase
Decrease
Considerable

8. How much of the time does the user have the discretion to disregard or alter the conclusions produced by the system?
0.0 1. $1-25 \%$
2. $26-50 \%$ 3. $51-75 \%$
4. $76-100 \%$

9. Is the user able to handle a wider or narrower range of problems with the system than prior to the implementation of the system?
$-2 \quad-1$
$0+1$
$+2$
Much Somewhat No Somewhat Much
Wider Wider Narrower Narrower

10. Relative to previous methods for doing the task, are there more are less decisions that can now be made immediately?
$-2$
$-1 \quad 0$
$+1+2$
Much More More The Same Less Much Less

11. At this time is the user of the system able to handle more or less work without supervision than previous to the implementation of the system.
$-2$
$-1 \quad 0$
$+1+2$
Much More More The Same Less Much Less 


\section{References}

Baldwin-Morgan, A.(1994) The impact of an expert system for audit planning: Evidence from a case study, International Journal of Applied Expert Systems. 2(3), 159-174.

Baldwin-Morgan, A.(1995) Studies of the impact of accounting-related expert systems: Comparison of methods, IEEE Conference on Artificial Intelligence Applications, IEEE Press, Washington, D.C., 72-77.

Carmichael, D. and Willingham, J.(1989) Auditing Concepts and Methods, McGraw Hill, New York.

Daft, R., and MacIntosh, N.(1978) A new approach to the design and use of management information, California Management Review. XXI:1, 82-92.

Dean, J., Yoon, S., and Susman, G.(1992) Advanced manufacturing technology and organisation structure, Organisational Science. 3(2).

Drucker, P.(1988) The coming of the new organisation, Harvard Business Review, January-February, 45-53.

Duchessi, P. and O' Keefe R.M. (1995)Understanding expert system success and failure, Expert Systems With Applications. 9(2), 123-133.

Kelly, K., Ribar, G., and Willingham, J. (1987) Interim report on the development of an expert system for the auditor's loan loss evaluation, Proceedings of the Touche Ross/University of Kansas Audit Symposium. 167-188.

Lynch, B.(1974) An empirical assessment of Perrow's technology construct, Administrative Science Quarterly, Sept. 338-356.

March, J. and Simon, H (1958) Organisations, New York, Wiley.

Messier, W. and Hansen, J. (1987) Expert systems in auditing: The state of the art, Auditing: A Journal of Theory and Practice. 7(1), 94-105.

Michaelsen, R. and Messier, W.(1987) Expert systems in taxation, Journal of The American Taxation Association. 7-21.

O' Keefe, R., O'Leary, D., Rebne, D., and Chung, Q.(1993) The impact of expert systems in accounting: System characteristics, productivity and work unit effects, International Journal of Intelligent Systems in Accounting, Finance and Management. 2(3), 177-189.

Orlikowski, W.(1992) The duality of technology: Rethinking the concept of technology in organisations, Organisational Science. 3(3).

Perrow, C.(1967) A framework for the comparative analysis of organisations, American Sociological Review. 194-208.

Perrow, C.(1970) Organisational Analysis: A Sociological View, New York, Tavistock publication.

Perrow, C.(1986) Complex Organisations, Random House, New York.

Sviokla, J.(1990) An examination of the impact of expert systems on the firm, MIS Quarterly. 14(2), $127-140$.

Trewin, J. (1996) The impact of an expert system on a professional accounting organisation, International Journal of Intelligent Systems in Accounting, Finance and Management. 5(3), 185-197.

Withey, M., Daft, R., and Cooper, W.(1983) Measures of Perrow's work unit technology: An empirical assessment of a new scale, Academy of Management Journal, 1983. 26(1), 45-63.

Correspondence and offprint requests to: Daniel E. O'Leary, School of Business, University of Southern California, Los Angeles, CA 90089-1421, USA. E-mail: oleary@rcf.usc.edu 